\title{
Coverage from the EANM 2013
}

On $19^{\text {th }}-23^{\text {rd }}$ October 2013 the annual congress of the European Association of Nuclear Medicine took place. This year specialists from all over Europe as well as guests from Asia and US visited Lyon, France. The event held at one of the biggest congress centers in Europe started on Saturday evening with an opening ceremony and welcome reception and lasted for four days. During the congress over 700 studies were presented, as well as over 1000 posters, including 148 featured at poster-walk sessions.

\section{Alfa-emitters in treating bone metastases}

Nuclear medicine applications in bone metastasis is a well known topic regarding Beta particle emitters eg. Strontium 89. However, the usefulness of Alfa emitters is not well recognized. The presentations concentrated on Radium 223 effect on treating patients with disseminated cancers, mainly breast and prostate cancer. While the first one remains in the clinical studies phase, the latter has been approved by FDA.

The ALSYMPCA study compared Radium223 vs placebo in 921 prostate cancer patients divided in two groups (2:1). The results show the survival longer by 3,6 months in the Radium group and time to skeletal related event longer by 5,8 months [1].

\section{Cardiologic Sessions}

Many cardiologic sessions were held. Session focused on myocardial viability presented the usefulness of SPECT and PET in recognizing viable myocardium, thus selecting patients more likely to benefit from invasive therapy. The main conclusion is that PET remains the most sensitive and specific tool concerning viability, however MRI may have an advantage in a group of patients with subendocardial infarction [2-5].

Other sessions highlighted the development of CZT cameras which allow us to significantly reduce the radiation dose and acquisition time, while improving the resolution of images. [6] Authors also presented TID (Transient Ischemic Dilation) and global wall thickening as independent risk factors of myocardial incident $[7,8]$.

\section{Hematology and oncology}

Most studies focused on applications of PET-CT in monitoring cancer. A study on 135 patients showed benefits of using PET-CT in radiotherapy planning in stage 1 and 2 Hodgkin Lymphoma patients [9].

A retrospective study of 1000 cases of lymphoma pointed out the need of radiation dose reduction during follow-up, especially when young patients undergo the treatment [10]. Presenta-

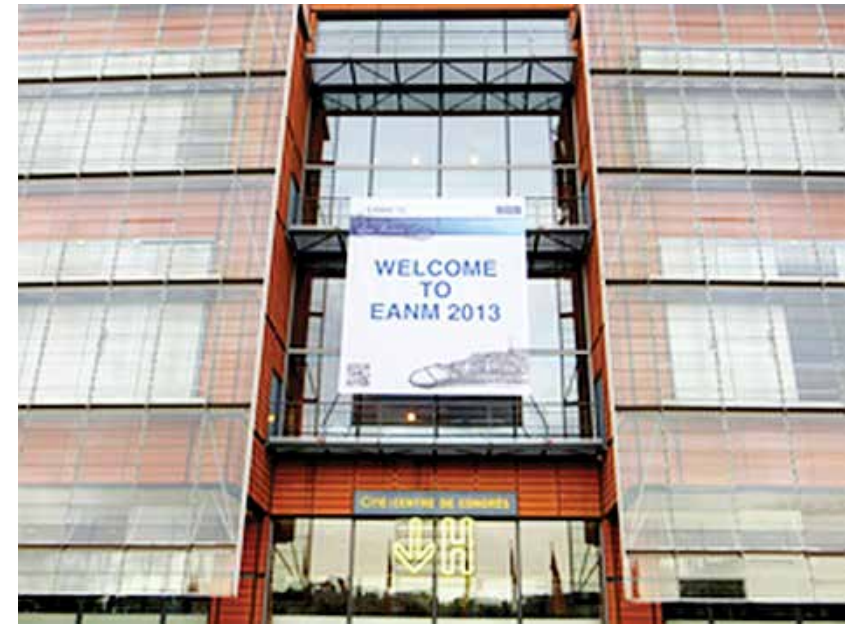

tions about ovarian cancer started the discussion in which the shortcomings of CA125 marker and CT where pointed out in context of PET-CT advantages [11, 12]

\section{Summary}

It is impossible to write about all of the sessions. During the whole congress, apart from scientific presentations, visitors could attend diagnostic and therapeutic equipment exhibitions. The event ended with highlights lecture and awards and closing ceremonies. The next congress will be held in October 2014 in Goeteborg, Sweden.

1. Alpha emitter radium-223 and survival in metastatic prostate cancer. Parker C, Nilsson S et al. for the ALSYMPCA Investigators. N Engl J Med 2013; 369: 213-223

2. Critical appraisal of viability assesment. Verberne HJ. EANM 2013; OP202.

3. SPECT and PET/CT assesment. Uebleis C. EANM 2013; OP203.

4. Cardiac magnetic resonance assesment. Lombardi M. EANM 2013; OP204.

5. Multimodality interpretation and comparison. Schindler TH. EANM 2013; OP205.

6. Impact of CZT cameras in the daily practice of nuclear cardiology: results from a French survey. Manrique A, Rouzet F, Djaballah W. The French Working Group of Nuclear Cardiology. EANM 2013; OP227.

7. Transient ischemic dilation in diabetic patients: prognostic value and impact on clinical outcome after coronary revascularization. Assante R, Petretta M, Acampa W et al. EANM 2013; OP166.

8. SPECT wall thickening prognostic value. Dercle $\mathrm{L}$, Lairez $\mathrm{O}$, Cognet $\mathrm{T}$ et al. EANM 2013; OP170.

9. Role assessment of FDG-PET on involved node radiotherapy (INRT) implementation in Hodgkin lymphoma patients. Edeline $V$ et al. EANM 2013; OP448. 
10. Limited 18F-FDG PET-CT for monitoring early chemotherapy response in lymphoma for reducing total radiation exposure. Sonoda $\mathrm{LI}$ et al. EANM 2013; OP450.

11. Role of 18F-FDG PET/CT in prognostication of advanced ovarian carcinoma patients in complete remission after primary treatment - a prospective study. Soundararajan R et al. EANM 2013; OP 331.
12. Role of 18F-FDG PET/CT in detection of suspected recurrent ovarian cancer: correlation with serum CA-125 and CT imaging. Rensi M et al. EANM 2013; OP332.

Sebastian Osiecki Nuclear Medicine Department Military Institute of Medicine Warsaw 